\title{
Breast cancer mortality in neighbouring European countries with different levels of screening but similar access to treatment: trend analysis of WHO mortality database
}

\author{
Philippe Autier research director ${ }^{1}$, Mathieu Boniol senior statistician ${ }^{1}$, Anna Gavin director ${ }^{2}$, Lars J \\ Vatten professor ${ }^{3}$
}

${ }^{1}$ International Prevention Research Institute, 95 Cours Lafayette, 69006 Lyon, France; ${ }^{2}$ Northern Ireland Cancer Registry, Belfast, Northern Ireland, UK; ${ }^{3}$ Department of Public Health, Norwegian University of Science and Technology, Trondheim, Norway

\begin{abstract}
Objective To compare trends in breast cancer mortality within three pairs of neighbouring European countries in relation to implementation of screening.

Design Retrospective trend analysis.

Setting Three country pairs (Northern Ireland (United Kingdom) $v$ Republic of Ireland, the Netherlands $v$ Belgium and Flanders (Belgian region south of the Netherlands), and Sweden $v$ Norway).

Data sources WHO mortality database on cause of death and data sources on mammography screening, cancer treatment, and risk factors for breast cancer mortality.

Main outcome measures Changes in breast cancer mortality calculated from linear regressions of log transformed, age adjusted death rates. Joinpoint analysis was used to identify the year when trends in mortality for all ages began to change.

Results From 1989 to 2006, deaths from breast cancer decreased by $29 \%$ in Northern Ireland and by $26 \%$ in the Republic of Ireland; by $25 \%$ in the Netherlands and by $20 \%$ in Belgium and $25 \%$ in Flanders; and by $16 \%$ in Sweden and by $24 \%$ in Norway. The time trend and year of downward inflexion were similar between Northern Ireland and the Republic of Ireland and between the Netherlands and Flanders. In Sweden, mortality rates have steadily decreased since 1972, with no downward inflexion until 2006. Countries of each pair had similar healthcare services and prevalence of risk factors for breast cancer mortality but differing implementation of mammography screening, with a gap of about 10-15 years.

Conclusions The contrast between the time differences in implementation of mammography screening and the similarity in reductions in mortality between the country pairs suggest that screening did not play a direct part in the reductions in breast cancer mortality.
\end{abstract}

\section{Introduction}

Deaths from breast cancer are decreasing in North America, Australia, and most Nordic and western European countries. ${ }^{1-3}$ After more than 20 years of intensive mammography screening in some of these countries, however, it is still difficult to determine how much of the observed reduction in mortality can be attributed to earlier detection of breast cancer or to improved management. ${ }^{45}$ This difficulty stems from the limited ability of most observational and modelling studies to disentangle the effects of early detection, treatment, and efficiency of healthcare systems on mortality. ${ }^{6}$

Deaths from cervical cancer have decreased substantially in the same countries. ${ }^{37}$ Reductions in cervical cancer mortality in Nordic countries from 1965 to 1980 were related to nationwide screening programmes from the 1960s (Iceland, Finland). In countries where screening programmes were delayed (Norway), the reduction in mortality became apparent many years later. Finland implemented a nationwide cytology screening programme in the 1960s, and from 1970 to 1980 mortality from cervical cancer decreased by $50 \%$. In Norway, a nationwide programme was implemented 15 years later, and from 1970 to 1980 mortality from cervical cancer decreased by only $8 \%$.

Access to surgery and radiotherapy was comparable between the Nordic countries, and the clear differences in mortality trends could be attributed to time differences in the implementation of screening. These data remain the most compelling evidence that cytology screening reduces mortality from this cancer. ${ }^{89}$

Studies of cervical cancer mortality at the population level suggest an approach that may help clarify the effectiveness of mammography screening. A review of randomised trials on mammography screening carried out by an international expert group suggested that in areas with screening attendance of at least $70 \%$, a reduction in breast cancer mortality by about $25 \%$ 
may be expected in women screened between 50 and 69 years of age and by about $19 \%$ in women screened between 40 and 49 years. ${ }^{6}$ Bearing in mind the experience with cytology screening for cervical cancer, the reduction in mortality in countries that implemented mammography screening early would be expected to appear before any reduction in similar countries with later implementation of screening.

We assessed trends in breast cancer mortality in pairs of neighbouring European countries where mammography screening had been implemented many years apart. We also examined potential factors that could mask the influence of screening on trends in mortality observed within each pair.

\section{Methods}

We selected pairs of European countries based on three criteria: the countries had to be neighbours; the countries had to have similar population structure, socioeconomic circumstances, quality of healthcare services, and access to treatment; and nationwide mammography screening in one country had to have existed since around 1990, with implementation some years later in the matched country. From information on mammography screening activities we summarised the population structure (for example, life expectancy, proportions of women in screening ages), socioeconomic circumstances, cultural environment, educational level, quality of healthcare services, and access to treatment for the 27 member states of the European Union, plus Norway, Switzerland, and Iceland. From these data, three pairs of countries met the selection criteria: Sweden and Norway, the Netherlands and Belgium, and Northern Ireland (United Kingdom) and the Republic of Ireland. For Belgium, we also sought data specific to the Flanders region, the area directly neighbouring the Netherlands where $60 \%$ of the Belgian population lives. We chose to take a closer look at Flanders as its medical culture, cultural background, socioeconomic status, language, and access to treatments are similar to those in the Netherlands. Belgium comprises two other regions, Brussels (10\% of the population) and Wallonia (30\% of the population), where French is spoken and where cultural patterns are more like those of France. Moreover, the organisation of mammography screening in Flanders was similar to the organisation in the Netherlands, whereas this was not the case for Brussels and Wallonia.

\section{Breast screening activities}

Using information from published peer reviewed articles or reports we summarised mammography screening activities in each country for the 1990s and 2000-5. 10-22 $^{2}$ We defined organised screening as a population based programme to which women of defined ages were regularly invited to screening mammography. Non-organised screening was defined as screening left to the discretion of the women or doctors, without any centrally organised invitation or follow-up systems. In non-organised screening, women aged 40-49 seemed to be screened at least as frequently as women aged 50-69. For Sweden and Norway we used data on year of first invitation to screening. For Belgium, the Netherlands, Northern Ireland, and the Republic of Ireland we extracted data on attendance for screening in the past two years (three years in the United Kingdom) by women aged 50-64 or 50-69 (depending on eligibility in the respective organised programmes), whatever the screening modality.

\section{Breast cancer mortality data}

We extracted data on deaths from breast cancer registered in the World Health Organization mortality database as of May 2010 for the six countries for 1980 to $2006 .{ }^{23}$ In addition to WHO data, we obtained information on mortality statistics for Belgium. Specific mortality rates for Belgium were recorded until 1997, after which they became available for Flanders and Brussels until 2006, whereas for Wallonia mortality data were available only for 2004. For Wallonia we estimated mortality rates from 1998 to 2003, and for 2005 and 2006 by linear interpolation calculated with data for 2004 for all the countries and using data from 1989 and 2004 for Flanders and the Brussels region as a proxy for time trends in Belgium. We then estimated a national mortality rate for Belgium using regional rates weighted by population size.

\section{Statistical analysis}

We used the age distribution of the European standard population to obtain European standardised age adjusted mortality rates. The analysis of trends in rates was based on knowledge that in 1989 a national screening programme was implemented in Sweden and that programmes were starting in Northern Ireland and the Netherlands. We fitted country specific Poisson regression models from 1989 until 2006 using annual numbers of breast cancer deaths and corresponding numbers of women by five year age groups. For the Poisson regression model specific to Flanders, we obtained annual population data by five year age groups from the Statistics Belgium for 1989 to 2004. For 1980-9, we used five year age groups reported by the population census in $1981^{24}$ and age specific demographic groups available in 1989 for interpolating population numbers from 1982 to 1988 . From the slope of each country we derived the annual percentage change in breast cancer mortality and the overall percentage change from 1989 to 2006 (1989 to 2004 for Belgium). We carried out these analyses for women of all ages and for women aged less than 50, 40-49, 50-69, 70-79, and 70 years and older. Analysis by age group was not possible for Flanders because age specific and region specific mortality data were not available before 1997.

We analysed temporal trends in mortality among women of all ages using joinpoint regression, version 3.4.2 of the software from the surveillance research programme of the US National Cancer Institute. ${ }^{25}$ Joinpoint regression consists of fitting a straight line on a logarithmic scale to the trends in annual age standardised rates. While fitting the straight line, the joinpoint programme identifies (through permutation analysis) years during which statistically significant inflexions in trend occur. The user may decide a priori whether the programme should be allowed to identify one or several possible years during which significant inflexions occur. If only one joinpoint is allowed, then the programme will identify the year with the strongest change in trend. If two joinpoints are allowed, the programme will return the two years with the highest statistical significance. Joinpoint regression was done on data from 1980 to 2006 (1980 to 2004 for Belgium). We selected the minimum significant number of joinpoints identified from the permutation test and also extracted results for the model with one additional joinpoint. This enabled us to identify whether an additional non-significant downward trend could also be noticed.

\section{Confounders}

We examined several factors associated with breast cancer mortality, as differences in their prevalence could contribute to differences in mortality trends between country pairs. 
Of all lifestyle and reproductive factors, obesity (as measured by body mass index) at the time of cancer diagnosis seems to be the strongest factor associated with a poor prognosis. ${ }^{26} \mathrm{We}$ used the prevalence of obesity in women aged 18 and older around 2000 that was available for the six countries, ${ }^{27}{ }^{28}$ as well as data on obesity trends in the United Kingdom and the Republic of Ireland. ${ }^{29}$ The association of reproductive factors with breast cancer incidence is well established and the risk increases with decreasing fertility and increasing age at first birth. But the association with breast cancer mortality is less clear. ${ }^{26}$ However, we extracted figures on fertility (average number of children born alive per woman) and mean age at first birth from Eurostat ${ }^{27}$ and from other sources for Flanders ${ }^{30} 31$ and Northern Ireland. ${ }^{32} \mathrm{We}$ used the available figures for the earlier year quoted for both countries of a pair.

For the management of breast cancer, we extracted data from the 2008 Karolinska Institute report on expenditures and adoption of anticancer drugs. ${ }^{33}$ As indicators of curative activities against cancer, we used the sales of anticancer drugs (annual per capita average) from 1990 to 2005, the uptake of new anticancer drugs in general (as sales per three month periods) after their introduction in the country, and the uptake of trastuzumab (as sales per three month period) after its introduction in the country. For the last two indicators we compared countries with an ad hoc European average based on 13 countries (E13: Austria, Denmark, Finland, France, Germany, Republic of Ireland, Italy, the Netherlands, Norway, Spain, Sweden, Switzerland, and the United Kingdom). We found no data on tamoxifen use that would allow comparison between countries of each pair. We also used per capita expenditures on health (adjusted for purchasing power parities) extracted from the WHO statistical information system database. ${ }^{34}$

\section{Results}

\section{Sweden and Norway}

The national organised mammography screening programme in Sweden was implemented from 1986 onwards after a pilot study and the results of clinical trials carried out in the country in the 1970s and 1980s (table 1). ${ }^{10}$ In 1990 about $90 \%$ of Swedish women had received a first invitation. Nationwide coverage was attained in 1997 (fig 1). All women aged 50-69 are invited, but in most counties (60-70\%) women aged 40-49 are also invited. ${ }^{11}$ In half the counties women aged 70-74 are invited. Attendance for screening in Sweden has been consistently among the highest recorded in any country. ${ }^{12}$ Non-organised screening is uncommon.

The Norwegian organised mammography screening programme was initiated in 1996 as a pilot project in four counties, which include $40 \%$ of Norway's population (Akershus, Hordaland, Oslo, Rogaland). ${ }^{13}{ }^{14}$ Since then organised screening has been gradually implemented, with all women aged 50-69 invited every two years. By 2005 the programme had reached nationwide coverage. For the implementation of nationwide screening the time difference between Sweden and Norway was about 12 years. Non-organised screening was uncommon after implementation of the nationwide programme.

From 1989 to 2006, breast cancer mortality decreased by $16.0 \%$ in Sweden and by $24.1 \%$ in Norway (table 2 and fig 1 ).

\section{The Netherlands and Belgium}

In the Netherlands, a national organised mammography screening programme was initiated in 1989 (table 1). After gradual implementation, the programme reached full coverage in 1997. ${ }^{15}{ }^{16}$ Women aged 50-69 are invited to mammography every two years, and since 1998 women aged 70-74 are also invited. Figure 2 shows that participation in screening gradually increased from 1989 to 1996, and after 1997 it has remained constant at around $70-79 \%$. Non-organised screening is uncommon.

In Belgium, breast screening was left to the discretion of the women and doctors until 2001, after which a national screening programme was established. Population surveys before 1999 suggested that less than $30 \%$ of women in the 50-69 year age group had undergone mammography during the past two years (for screening or diagnostic purposes). ${ }^{17}$ Around 2000, about $30 \%$ of women aged 50-69 had undergone screening or diagnostic mammography in the past two years. ${ }^{18} 19$ By around 2005 this proportion had increased to about 59\% (fig 2). At that time two thirds of screening examinations were done as part of the organised programme in Flanders, and for less than one sixth in Brussels and Wallonia. Participation in screening (organised and non-organised) in Flanders was low until about 2002-3, and by 2004-6 it was still below the coverage in the Netherlands in 1997 (fig 2).

In the Netherlands the overall reduction in breast cancer mortality from 1989 to 2006 was slightly greater than in Belgium $(25.0 \% v 19.9 \%)$ but did not differ noticeably from Flanders (25.0\% v 24.6\%; table 2 and fig 2).

\section{Northern Ireland (United Kingdom) and Republic of Ireland}

The United Kingdom organised mammography screening programme was introduced in Northern Ireland at the beginning of the 1990s (table 1). ${ }^{20}$ It includes women aged 50-64, who are invited to screening every three years. In 2003-4 the age range was extended to women up to age 70 . Unlike the rest of the United Kingdom, Northern Ireland used two view mammography from the start. Attendance steadily increased during the 1990s and has remained stable, at around 70-75\%, since $1995 .^{21}$ Non-organised screening is uncommon.

A national organised mammography screening programme was introduced in the Republic of Ireland in 2000, firstly in the eastern part of the country and then over several years achieved nationwide coverage. Women aged 50-69 are invited every two years. Before that breast screening was left to the discretion of the women and doctors and coverage was low. In 2002 national coverage was about $30 \%$. It has gradually increased and in 2008 was $76 \% .^{22}$

From 1989 to 2006 , breast cancer mortality decreased by $29.6 \%$ in Northern Ireland and by $26.7 \%$ in the Republic of Ireland (table 2 and fig 3 ).

\section{Further comparisons}

Table 2 summarises mortality trends for all women and by age group. In Sweden, mortality trends had steadily decreased since $1972^{2}$ and screening implementation did not lead to a new inflexion in trends after 1972. In Northern Ireland and the Netherlands, mortality started to decrease shortly after screening was introduced. In Belgium, Norway, and the Republic of Ireland, mortality started to decrease years before most women in the target age groups attended screening. In these three countries, when a second joinpoint was forced, the second year of inflexion in mortality trends always occurred before most eligible women participated in the screening.

Overall, the greatest reduction in breast cancer mortality has occurred among younger women, aged 40 to 49 (table 2). This 
was also the case for Northern Ireland and Norway, where mammography screening before the age of 50 is rare. In women aged 70-79, the reduction in breast cancer mortality varied substantially by country, with strong reductions in the Netherlands, Norway, and the Republic of Ireland.

\section{Confounders}

Reproductive factors did not differ substantially within each pair (table 3). The prevalence of obese women was similar within each country pair, except that obesity was more prevalent in Northern Ireland than in the Republic of Ireland. (Since 1998, obesity in the Republic of Ireland has increased much faster than in Northern Ireland (data not shown), ${ }^{29}$ a situation that could have contributed to an increase in breast cancer mortality in the Republic of Ireland.)

The summary economic indicators suggest that average healthcare expenditures were higher in the Republic of Ireland and in Norway compared with Northern Ireland and Sweden, whereas the expenditures in Belgium and the Netherlands appeared to be similar. Uptake of recent anticancer drugs seemed to be slower in Northern Ireland than in the other countries. No data related to uptake of anticancer drugs were available for the Republic of Ireland.

Access to cancer treatment did not differ between the Netherlands and Belgium or between Sweden and Norway. In 2001, information on treatment suggested small differences between Northern Ireland and the Republic of Ireland. ${ }^{35}$ Compared with Northern Ireland, the Republic of Ireland had higher rates of chemotherapy $(49.8 \% v 38.4 \%)$, slightly lower rates of radiotherapy $(63.4 \% v 68.6 \%)$, and lower use of tamoxifen as adjuvant therapy $(47.7 v 75.6 \%){ }^{35}$

\section{Discussion}

Trends in breast cancer mortality rates varied little between countries where women had been screened by mammography for a considerable time compared with those where women were largely unscreened during that same period. This is in sharp contrast with the temporal difference of 10 to 15 years in implementation of mammography screening and suggests that screening has not played a direct part in the reductions of breast cancer mortality.

\section{Strengths and limitations of the study}

Our study is based on population level data, but its value goes beyond a simple ecological study because the three countries that implemented screening relatively late were otherwise closely matched to the countries where nationwide screening programmes started before 1991. By comparing changes in disease incidence or mortality between geographical areas that have implemented a certain intervention with otherwise similar areas without the intervention, the effectiveness of the intervention may be assessed. For instance, this method was recently used to assess the public health impact of the ban on smoking in public areas, using the subsequent incidence of acute myocardial infarction as outcome. ${ }^{36}$ Also, studies of mortality trends for cervical cancer in the Nordic countries used a similar approach and are considered to be the best evidence for the effectiveness of screening for cervical cancer. ${ }^{89}$

Studies at a population level are none the less limited by their inability to control confounding. It is therefore reasonable to question which factors could have caused the near absence of a difference in breast cancer mortality within the country pairs. We found no differences in risk factors for breast cancer or in access to treatment within each pair that could have counterbalanced the influence of screening associated with the decline in mortality. An as yet unknown confounding factor could obscure the relation between screening and mortality, but it is unlikely that this would have affected all three pairs simultaneously.

\section{Factors possibly explaining findings}

We also examined factors that could mask the interpretation of the data. Firstly, differences in the quality of registration of causes of death in country pairs is unlikely, mainly because the registration of deaths from breast cancer may be more reliable than for many other cancers. ${ }^{37}{ }^{38}$ Secondly, the six countries have a longstanding tradition of recording causes of death. Thirdly, WHO judged that the quality of cause of death data within each pair of countries was comparable: high quality in Northern Ireland and the Republic of Ireland and medium quality in the four other countries. ${ }^{39}$ Fourthly, we included information on non-organised (opportunistic) screening in Belgium and the Republic of Ireland using screening attendance statistics (table 1). In the four other countries, opportunistic screening is uncommon. ${ }^{11}$

\section{Comparison with other studies}

It may be questioned whether the observation period was long enough for reliable comparisons to be made. The Malmö randomised trial, which is usually considered as methodologically robust, showed reductions in mortality eight years after the start of screening. ${ }^{40-42}$ At the population level, however, longer follow-up is probably needed because implementation of screening in the population is likely to take more time, and in our study the observation period was 18 years. In the Netherlands, a 20 year mortality follow-up after introducing mammography screening in the city of Nijmegen in 1975 , showed that breast cancer mortality did not decline any earlier than in the city of Arnhem or in the Netherlands as a whole. ${ }^{43}$ Similar to our study, the investigators could not explain why the reduction did not start earlier in Nijmegen.

Mammography screening aims to detect cancer before it is clinically apparent and before it has developed to an advanced stage. As suggested by the randomised trials, widespread organised screening would be expected to reduce the incidence of advanced breast cancer that should be observable years before reductions in mortality. ${ }^{64}$ However, in another study we showed that contrary to expectations, the incidence of advanced breast cancer in Northern Ireland and the Netherlands remained quite stable (similar data are not available for Sweden) subsequent to the implementation of screening. ${ }^{45}$ Those results suggest that follow-up longer than the 18 years of the present study is not likely to change the differences in mortality trends between the countries of each pair.

\section{Year of start of the decline in mortality}

The decline in mortality started between 1991 and 1996 in Norway, Belgium, the Republic of Ireland, Northern Ireland, and the Netherlands. In Sweden, the decline in breast cancer mortality that started in 1972 has remained stable over time and the reduction after 1989 was modest compared with other European countries. ${ }^{1}$ Mammography screening cannot explain these changes in trends because the reduction in mortality started too soon after screening was implemented in the Netherlands and Northern Ireland, and because screening was still uncommon in the four other countries. It seems more likely that the downward inflexions observed from 1991 to 1996 stem from 
the impact of adopting effective anticancer treatments, as indicated by meta-analyses showing the positive influence of such treatments on survival of patients with breast cancer. ${ }^{46}$

\section{Age at death}

The greatest reductions in mortality were observed in women younger than 50, independent of mammography screening in that age group. The large mortality reduction in women aged 70 and older in the Netherlands has been interpreted as evidence for screening effectiveness. ${ }^{47}$ However, similar reductions were observed in Norway and the Republic of Ireland, and the reductions in these countries cannot be attributed to screening. It seems more plausible that the differences in reduction of mortality among older women may be due to differences between countries in the intensity of diagnostic efforts and treatment. $^{48-50}$

\section{Conclusions and policy implications}

The contrast between the timing of breast cancer screening being implemented and the similarity in mortality reduction between the country pairs do not suggest that a large proportion of the mortality reduction after 1990 can be attributed to mammography screening. Improvements in treatment and in the efficiency of healthcare systems may be more plausible explanations. Our study adds further population data to the evidence of studies that have used various designs and found that mammography screening by itself has little detectable impact on mortality due to breast cancer. ${ }^{1445152}$

Contributors: PA conceived and designed the study. All authors collected and interpreted the data, edited the manuscript, and approved the final version of the manuscript for submission. PA and MB analysed the data. $P A, A G$, and LJV wrote the manuscript. PA is the guarantor.

Funding: The institutions in which the authors work had no influence on the conduct of the research or the writing of the paper. The work of the Northern Ireland Cancer Registry is funded by the Public Health Agency for Northern Ireland.

Competing interests: All authors have completed the ICMJE uniform disclosure form at www.icmje.org/coi_disclosure.pdf (available on request from the corresponding author) and declare: no support from any organisation for the submitted work; no financial relationships with any organisations that might have an interest in the submitted work in the previous three years; no other relationships or activities that could appear to have influenced the submitted work.

Ethical approval: Not required.

Data sharing: The WHO mortality database is available at www.who. int.

1 Autier P, Boniol M, LaVecchia C, Vatten L, Gavin A, Héry C, et al. Disparities in breas cancer mortality trends between thirty European countries: retrospective trend analysis of WHO mortality database. BMJ 2010;341:c3620.

2 Héry C, Ferlay J, Boniol M, Autier P. Quantification of changes in breast cancer incidence and mortality since 1990 in 35 countries with Caucasian-majority populations. Ann Oncol 2008;19:1187-94.

3 Jemal A, Siegel R, Xu J, Ward E. Cancer statistics, 2010. CA Cancer J Clin 2010;60:277-300.

4 Berry DA, Cronin KA, Plevritis SK, Fryback DG, Clarke L, Zelen M, et al. Effect of screening and adjuvant therapy on mortality from breast cancer. N Engl J Med 2005;353:1784-92.

5 Jones AL. Reduction in mortality from breast cancer: screening and increased use of adjuvants are responsible_-adjuvants more so. BMJ 2005;330:205-6.

6 International Agency for Research on Cancer. IARC/WHO handbooks of cancer prevention vol 7: breast cancer screening. IARC Press, 2002.

7 Arbyn M, Raifu AO, Weiderpass E, Bray F, Anttila A. Trends of cervical cancer mortality in the member states of the European Union. Eur J Cancer 2009;45:2640-8.

8 Läärä E, Day NE, Hakama M. Trends in mortality from cervical cancer in the Nordic countries: association with organized screening programmes. Lancet 1987;i:1247-9.

9 International Agency for Research on Cancer. IARC/WHO handbooks of cancer prevention vol 10: cervix cancer screening. IARC Press, 2005.

10 Olsson S, Andersson I, Karlberg I, Bjurstam N, Frodis E, Håkansson S. Implementation of service screening with mammography in Sweden: from pilot study to nationwide programme. J Med Screen 2000;7:14-8.
11 Von Karsa L, Antilla A, Ronco G, Ponti A, Malila N, Arbyn M, et al. Cancer screening in the European Union, report on the implementation of the council recommendation on cancer screening, first report, Directorate General Health and Consumers, European Communities. 2008. http://ec.europa.eu/health/ph_determinants/genetics/documents/ cancer_screening.pdf.

12 Swedish Organised Service Screening Evaluation Group. Reduction in breast cancer mortality from organized service screening with mammography: 1 . Further confirmation with extended data. Cancer Epidemiol Biomarkers Prev 2006:15:45-51.

13 Hofvind S, Geller B, Vacek PM, Thoresen S, Skaane P. Using the European guidelines to evaluate the Norwegian Breast Cancer Screening Program. Eur J Epidemiol 2007;22:447-55.

14 Kalager M, Zelen M, Langmark F, Adami HO. Effect of screening mammography on breast-cancer mortality in Norway. N Engl J Med 2010;363:1203-10.

15 Fracheboud J, Otto SJ, van Dijck JA, Broeders MJ, Verbeek AL, de Koning HJ. Decreased rates of advanced breast cancer due to mammography screening in The Netherlands. $B r$ $J$ Cancer 2004;91:861-7.

16 National Evaluation Team for Breast Cancer Screening. NETB interim report 2007. Main results of breast cancer screening programme in The Netherlands. NETB, 2007.

17 Vandenbroucke A, Bourdon C. Breast cancer screening programmes-results of studies in foreign countries-situation in Belgium. Eur J Cancer Prev 1993:2:269-74.

18 De Bock C, Fabri V, Remacle A. Succès contrastés du programme de dépistage du cancer du sein. Education Santé, No 246. 2009. [French.] www.educationsante.be/es/article. php?id=1127.

19 Fabri V, Remacle A. Programme de dépistage du cancer du sein: comparaison des trois premiers tours 2001-2002, 2003-2004 et 2005-2006. Rapport numéro 6 de l'Agence Intermutualiste. [French and Dutch.] 2009. www.nic-ima.be/fr.

20 Kee F, Telford AM, Donaghy P, O'Doherty A. Attitude or access: reasons for not attending mammography in Northern Ireland. Eur J Cancer Prev 1992;1:311-5.

21 HSC Public Health Agency. NI cancer screening programmes. 2011. www.cancerscreening n-i.nhs.uk/statistics/.

22 BreastCheck-The National Breast Screening Programme. Programme report 2008/09. Irish National Cancer Screening Service Ireland, 2009.

23 World Health Organization. Mortality database. 2010. www.who.int/healthinfo/morttables.

24 Institut National de Statistiques. Recencement de la population et des logements au $1^{\text {er }}$ mars 81. 1982. http://economie.fgov.be/fr/binaries/01_fr_tcm326-33744.pdf.

25 National Cancer Institute. Joinpoint regression program, version 2.7. 2011. www.srab. cancer.gov/joinpoint/.

26 Barnett GC, Shah S, Redman K, Easton DF, Ponder BAJ, Pharoah PDP. Risk factors fo the incidence of breast cancer: do they affect survival from the disease? J Clin Oncol 2008;26:3310-6.

27 European Commission. Eurostat database. 2011. http://ec.europa.eu/eurostat/.

28 Boniol M, Autier P. Prevalence of main cancer lifestyle risk factors in Europe in 2000. Eur $J$ Cancer 2010;46:2534-44

29 Association of Public Health Observatories. International comparisons of obesity prevalence. National Obesity Observatory, National Health Service (NFS), 2009.

30 Van Bavel J, Bastiaenssen V. De evolutie van de vruchtbaarheid in het Vlaamse Gewest tussen 2001 en 2005. Interface demography working paper:2006-1. 2006. www.vub.ac. be/SOCO/demo/intro.htm.

31 Goed Gevoel. Gezondheid/psycho. [Dutch.] 2011. www.goedgevoel.be/gg/nl/449/Geboorte article/detail/1126704/2010/06/29/Vrouw-nooit-zo-oud-bii-geboorte-eerste-kind dhtml.

32 Statistics Press Notice. Births in Northern Ireland (2006). Northern Ireland Statistics and Research Agency, 2007.

33 Jonsson B, Wilking $\mathrm{N}$. A global comparison regarding patient access to cancer drugs Ann Oncol 2007;18(suppl 3):1-74.

34 WHO Statistical Information System. 2011. www.who.int/whosis/

35 Donnelly DW, Gavin AT, Comber H. Cancer in Ireland 1994-2004: a summary report. 2009. www.qub.ac.uk/nicr.

36 Herman PM, Walsh ME. Hospital admissions for acute myocardial infarction, angina, stroke, and asthma after implementation of Arizona's comprehensive statewide smoking ban. Am J Public Health 2011;101:491-6.

37 Doll R, Peto R. The causes of cancer. Oxford University Press, 1981.

38 Nyström L, Andersson I, Bjurstam N, Frisell J, Nordenskjöld B, Rutqvist LE. Long-term effects of mammography screening: updated overview of the Swedish randomised trials. Lancet 2002:359:909-19.

39 Mathers CD, Ma Fat D, Inoue M, Rao C, Lopez A. Counting the dead and what they died from: an assessment of the global status of cause of death data. Bull World Health Org 2005;83:171-7.

40 Andersson I, Aspegren K, Janzon L, Landberg T, Lindholm K, Linell F, et al. Mammographic screening and mortality from breast cancer: the Malmö mammographic screening trial. BMJ 1988;297:943-8.

41 Anderson I, Nystrom L. Mammography screening. J Nat/ Cancer Inst 1995;87:1263-4.

42 Miettinen OS, Henschke Cl, Pasmantier MW, Smith JP, Libby DM, Yankelevitz DF. Mammography screening: no reliable supporting evidence? Lancet 2002;359:404-6.

43 Broeders MJM, Peer PGM, Straatman H, Beex LVAM, Hendriks JHCL, Holland R, et al. Diverging breast cancer mortality rates in relation to screening? A comparison of Nijmegen to Arnhem and The Netherlands, 1969-1997. Int J Cancer 2001:92:303-8.

44 Autier P, Héry C, Haukka J, Boniol M, Byrnes G. Advanced breast cancer and breast cancer mortality in randomized controlled trials on mammography screening. J Clin Oncol 2009;27:5919-23.

45 Autier P, Boniol M, Middleton R, Doré JF, Héry C, Zheng T, et al. Advanced breast cance incidence following population-based mammographic screening. Ann Oncol 2011; published online 20 January.

46 Early Breast Cancer Trialists' Collaborative Group. Effects of adjuvant tamoxifen and of cytotoxic therapy on mortality in early breast cancer: an overview of 61 randomised trials among 28,896 women. N Engl J Med 1988;319:1681-92.

47 Otten JD, Broeders MJM, Fracheboud J, Otto SJ, de Koning HJ, Verbeek ALM. Impressive time-related influence of the Dutch screening programme on breast cancer incidence and mortality, 1975-2006. Int J Cancer 2008;123:1929-34.

48 Siebel MF, Muss HB. The influence of aging on the early detection, diagnosis, and treatment of breast cancer. Curr Oncol Rep 2005;7:23-30.

49 Eaker S, Dickman PW, Bergkvist L, Holmberg L. Differences in management of older women influence breast cancer survival: results from a population-based database in Sweden. PLoS Med 2006;3:e25.

50 Bernardi D, Errante D, Galligioni E, Crivellari D, Bianco A, Salvagno L, et al. Treatment of breast cancer in older women. Acta Oncol 2008;47:187-98. 


\section{What is already known on this topic}

Breast cancer mortality is decreasing in many countries but the association with mammography screening is difficult to appraise

Cervical cancer mortality decreased earlier and more strongly in those Nordic countries that implemented nationwide screening programmes compared with delayed screening

\section{What this study adds}

Breast cancer mortality in paired European countries with similar socioeconomic status and access to treatment were comparable after 1989, despite a 10-15 year difference in implementation of mammography screening

The downward trends in mortality started before or shortly after the implementation of the screening programme

The greatest reductions were in women aged 40-49, regardless of the availability of screening in this age group; reductions in women aged 70-79 were highly variable and did not correlate with the timing of screening in younger age groups

51 Esserman $\mathrm{L}$, Shieh $\mathrm{Y}$, Thompson I. Rethinking screening for breast cancer and prostate cancer. JAMA 2009;302:1685-92.

Cite this as: BMJ 2011;343:d4411

2 Jørgensen KJ, Zahl PH, Gøtzsche PC. Breast cancer mortality in organised mammography screening in Denmark: comparative study. BMJ 2010;340:c1241. 


\section{Tables}

Table 1 | Indicators of mammography screening activities in country pairs

\begin{tabular}{|c|c|c|c|c|c|c|}
\hline \multirow[t]{2}{*}{ Characteristics } & \multicolumn{6}{|c|}{ Country pairs } \\
\hline & $\begin{array}{l}\text { Northern } \\
\text { Ireland }\end{array}$ & $\begin{array}{l}\text { Republic of } \\
\text { Ireland }\end{array}$ & Netherlands & Belgium, Flanders & Sweden & Norway \\
\hline $\begin{array}{l}\text { Predominant type of } \\
\text { screening activities, 1995-9 }\end{array}$ & $\begin{array}{l}\text { Organised } \\
(1990)\end{array}$ & Non-organised & $\begin{array}{l}\text { Organised } \\
(1989)\end{array}$ & $\begin{array}{l}\text { Non-organised, } \\
\text { non-organised }\end{array}$ & $\begin{array}{l}\text { Organised } \\
(1986)\end{array}$ & $\begin{array}{l}\text { Organised (1996 } \\
\text { in } 4 / 19 \text { counties) }\end{array}$ \\
\hline $\begin{array}{l}\% \text { of women aged } 50-69 \\
\text { screened, } 1995-9^{*}\end{array}$ & $>70$ & $<30$ & $>70$ & $<30,<30$ & $>80$ & $<30$ \\
\hline $\begin{array}{l}\text { Predominant type of } \\
\text { screening activities, } 2000-5^{\star}\end{array}$ & Organised & $\begin{array}{l}\text { Non-organised and } \\
\text { organised (2000) }\end{array}$ & Organised & $\begin{array}{l}\text { Non-organised and } \\
\text { organised (2001), } \\
\text { organised (2001) and } \\
\text { non-organised }\end{array}$ & Organised & Organised \\
\hline $\begin{array}{l}\% \text { of women screened, } \\
2000-5^{\star}\end{array}$ & $>70$ & 50 & $>75$ & 50,50 & $>80$ & $>70$ \\
\hline $\begin{array}{l}\text { Age groups invited to } \\
\text { organised screening } \\
\text { (interval in years), } 2005\end{array}$ & $50-64(3)$ & $50-64(2)$ & $50-74(2)$ & $50-69(2), 50-69(2)$ & $40-74(2) \dagger$ & $50-69(2)$ \\
\hline
\end{tabular}

See text for data source references. Bracketed dates are year of start of programme unless stated otherwise.

*Screening of women less than 50 is common in non-organised screening.

tInterval every 18 months for age group 40-49. 
Table 2| Changes in breast cancer mortality between 1989 and 2006 in country pairs

\begin{tabular}{|c|c|c|c|c|c|c|c|c|}
\hline \multirow[b]{2}{*}{ Country } & \multicolumn{2}{|c|}{ Mean mortality rate } & \multirow[b]{2}{*}{$\begin{array}{c}\text { Overall } \% \text { change } \\
1989-2006\end{array}$} & \multirow{2}{*}{$\begin{array}{l}\text { Joinpoint year for } \\
\text { start of decrease } \\
\text { after } 1980^{\star}\end{array}$} & \multirow{2}{*}{$\begin{array}{l}\text { Joinpoint years when } \\
\text { forcing one additional } \\
\text { joinpoint }\end{array}$} & \multicolumn{3}{|c|}{ Overall $\%$ change $1989-2006$ by age group } \\
\hline & $1987-9$ & 2004-6 & & & & $40-49$ & $50-69$ & $70-79$ \\
\hline Northern Ireland & 37.0 & 28.1 & -29.6 & 1991 & 1994/1997 & -50.7 & -36.7 & -11.1 \\
\hline Republic of Ireland & 40.3 & 30.5 & -26.7 & 1991 & $1984 / 1989$ & -45.2 & -27.7 & -18.7 \\
\hline Netherlands & 39.0 & 30.1 & -25.0 & 1994 & 1991/1999 & -25.2 & -28.0 & -26.7 \\
\hline Belgium $\ddagger$ & 37.5 & 29.7 & -19.9 & 1996 & 1986/1996 & -37.5 & -21.4 & -14.1 \\
\hline Flanders & 38.9 & 30.1 & -24.6 & 1996 & $1982 / 1996$ & NA & NA & NA \\
\hline Sweden & 25.6 & 22.0 & -16.0 & No joinpoint yeart & $1992 / 2006$ & -35.5 & -16.0 & -9.7 \\
\hline Norway & 27.4 & 21.5 & -24.1 & 1994 & $1993 / 1995$ & -33.5 & -22.8 & -22.8 \\
\hline
\end{tabular}

$\mathrm{NA}=$ not available.

*Joinpoint year of statistical significant at $\mathrm{P}<0.05$ (two sided).

†Last joinpoint year was $1972 .^{2}$

fUntil 2005 
Table 3| Factors possibly associated with breast cancer mortality in country pairs

\begin{tabular}{|c|c|c|c|c|c|c|c|}
\hline \multirow[b]{2}{*}{ Country } & \multirow[b]{2}{*}{ Fertility* (year) } & \multirow[b]{2}{*}{$\begin{array}{c}\text { Mean age at first } \\
\text { birth (year) }\end{array}$} & \multirow{2}{*}{$\begin{array}{c}\% \text { women } \\
\text { with body } \\
\text { mass index } \\
\geq 30\end{array}$} & \multicolumn{2}{|c|}{ Per capita expenditures } & \multicolumn{2}{|c|}{ Drug uptake $v E 13$ average } \\
\hline & & & & $\begin{array}{c}\text { Health in } 2005 \\
\text { (PPP international } \\
\text { US\$) }\end{array}$ & $\begin{array}{c}\text { Anticancer drug } \\
\text { sales }(€), \\
<1995-2005\end{array}$ & Anticancer drugs & Trastuzumab \\
\hline Northern Ireland & $2.7(1978)$ & $25.0(1978)$ & 23.2 & 2598 & 12.5 & Slow & Below \\
\hline $\begin{array}{l}\text { Republic of } \\
\text { Ireland }\end{array}$ & $3.2(1980)$ & $25.5(1980)$ & 10.6 & 3125 & NA & NA & NA \\
\hline Netherlands & $\begin{array}{c}3.1(1960) / 2.4 \\
(1971)\end{array}$ & $\begin{array}{c}24.8(1960) / 26.6 \\
(1985)\end{array}$ & 10.2 & 3187 & 17.9 & Average & Below \\
\hline Belgium & $\begin{array}{c}2.6(1960) / 2.2 \\
(1971)\end{array}$ & $\begin{array}{c}25.5(1960) / 25.5 \\
(1985)\end{array}$ & 11.9 & 3071 & 19.1 & Average & Average \\
\hline Flanders & $\begin{array}{c}\text { NA }(1960) / 2.2 \\
(1971)\end{array}$ & $\begin{array}{c}\text { NA }(1960) / 25.7 \\
(1987)\end{array}$ & NA & NA & NA & NA & NA \\
\hline Sweden & $\begin{array}{c}2.2(1968) / 2.1 \\
(1980)\end{array}$ & $26.3(1990)$ & 9.0 & 3012 & 19.4 & Average & Average \\
\hline Norway & $\begin{array}{c}2.9(1968) / 1.9 \\
(1980)\end{array}$ & $25.6(1990)$ & 7.0 & 4331 & 15.5 & Average & Below \\
\hline
\end{tabular}

$€ 1.00$ (£0.88; \$1.41).

See methods section for data sources and list of E13 (European) countries. PPP=purchasing power parity; $N A=$ not available.

*Mean number of children born alive per woman. 


\section{Figures}

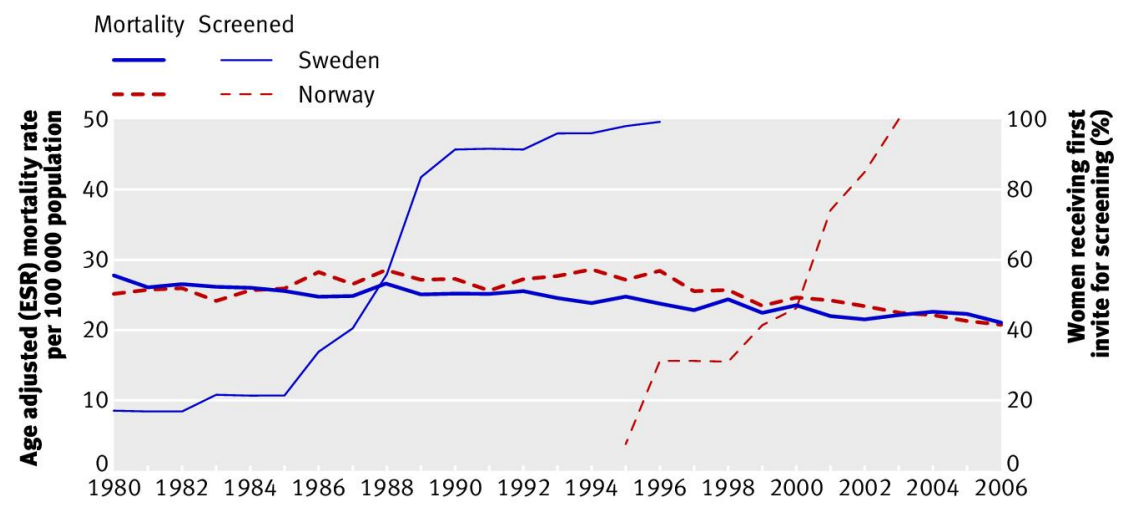

Year

Fig 1 Year of first invitation for mammography screening and age adjusted (European standardised rates) breast cancer mortality in women of all ages in Sweden and Norway

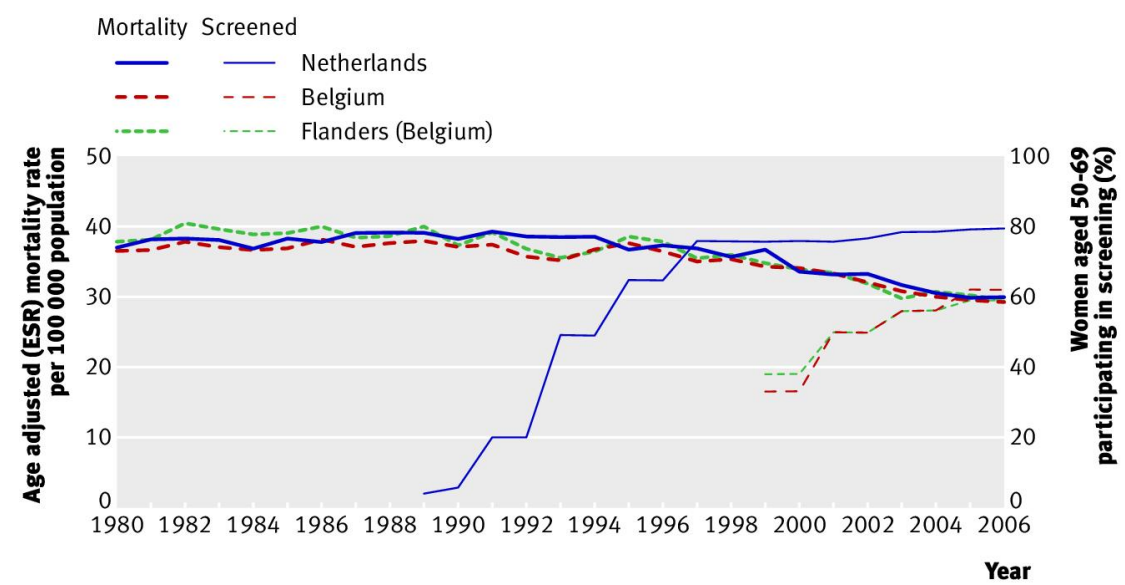

Fig 2 Participation in mammography screening and age adjusted (European standardised rates) breast cancer mortality in women of all ages in the Netherlands and Belgium

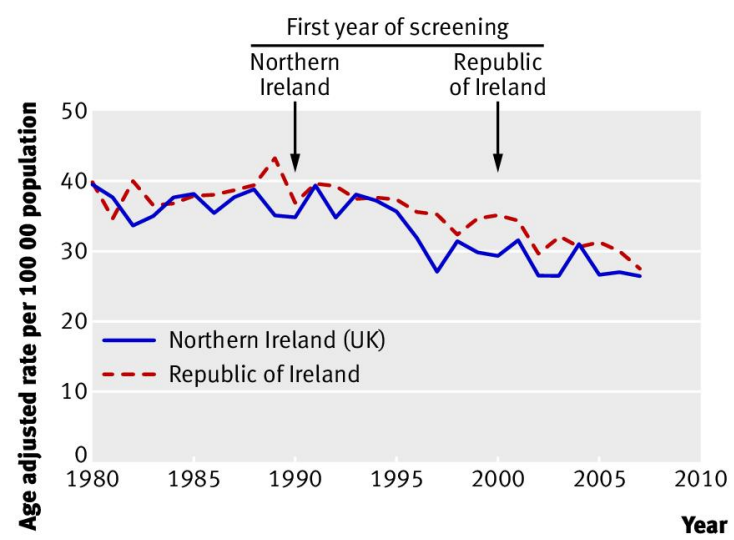

Fig 3 First year of organised screening programme and age adjusted (European standardised rates) breast cancer mortality in Northern Ireland and Republic of Ireland 